\title{
Technophilia and technophobia
}

\section{Michael G Campion \\ Murdoch University}

One of the sub-themes of the International Educational Technology Conference held in Perth, Western Australia in December 1986, "Education for a technological society", provided us with an opportunity to discuss whether educational technologists should, or should not, locate their work within broader debates about technological change. It will become clear as I proceed that I am of the opinion that they should, though I am far from convinced that they do.

Bernard Levin wrote in the late 60s that he had begun to suspect that "... a long period of purgatory has got to be gone through before we reach the computerized Kingdom of Heaven", and that "we are presently stuck well into it" (Martin \& Norman, 1973, p.407). The first point we should notice here is the sense of optimism we are expected to reach the computerized Kingdom of Heaven. Others, of course, hold far more pessimistic views of the future. Lowi for example refers to the fact that "educational institutions are uniquely capable of programming the individual for a full life of comfort within the Hell of Administrative Boredom" (Lowi, 1982, p.469). The analogies are both religious and either utopian or dystopian and it is not uncommon for debates about technology to be couched either explicitly or implicitly in conceptual frameworks of this kind. So for example Walter Mathews' (1980) work about the impact of computers upon society is entitled Monster or Messiah. Alan Roberts (1979) article in Arena is entitled "Technology as Hope and Threat" and M. Cooley s (1980) book is called Architect or Bee.

Langdon Winner (1977) in his work Autonomous Technology addresses the issue of religious analogies. He states that: 
While such analogies of religious crisis help to illuminate the outrage present in much of the contemporary criticism of technology, they fail to capture an important characteristic of the discussion -its pervasive sense of puzzlement and disorientation. The writers who have isolated technology as an issue have repeatedly stressed that what is involved is not merely a problem of values or faith but, more importantly, a problem in our understanding of things. There is, they assert, something wrong in the way we view technology and mans relationship to it. In its present array of vast and complex forms, technology continually surprises us and baffles our attempts at comprehension. From all sides one hears the call for new evidence and new interpretations to remedy our disoriented state. (p.10)

He goes on to say:

It soon becomes clear that in this enlightened age there is almost no middle ground of rational discourse, no available common language with which persons of differing backgrounds can discuss matters of technology in thoughtful, critical terms. Conversations gravitate toward warring polarities and choosing sides. (p.11)

Now this article will not provide the middle ground Winner suggests is required for rational discourse for I willingly confess that I am baffled by the complexity of the issues involved and yet I am persuaded that we, in the sphere of education, need now more than ever, to risk bringing these matters to the fore. Perhaps at best this article will help us to reconsider our agenda.

In the first section of this article I want to pursue the issue of gravitation towards warring polarities mentioned by Winner through a brief discussion of the notions of technophilia and technophobia.

In the second I shall relate these opposing perspectives to certain aspects of social class theory in order that we can better grasp their social rather than their apparently personal significance.

In the third section I shall present an argument which is designed to show how these opposed perspectives are only rational if certain assumptions are accepted without question. Assumptions which are grounded in mythical notions of technology and technological change.

In the fourth section I shall introduce a number of different versions of what has been referred to in the conference sub-theme as a technological society and then consider some possible implications of these for higher education.

1. Technophilia and Technophobia - this pair of concepts are closely related to the notions of cyberphilia and cyberphobia presented in a pair of articles represented in the work edited by Van Tassel and Van Tassel 
(Wrege, 1983) entitled The Compleat Computer. It seems to me that reference to technology rather than cybernetics is both more readily accessible and of a more general application, and that on these grounds it might be preferred. Badham (1984, p.62) refers to the pair of concepts technocratic and technophobic, however whilst the former term is common in contemporary usage it misleadingly, in my view, suggests that reason supports those who favour technology where emotion or perhaps a lack of reason motivates those who fear, or are opposed to technology. Again it seems to me that the pair of terms technophilia and technophobia reveal in a more evenly balanced fashion the possibly irrational basis of both commitments.

I will risk referring to Langdon Winner's work once again, for he provides us with a succinct general statement on this particular issue:

... the confusion surrounding the concept "technology" is an indication of a kind of lag in public language, that is, a failure of both ordinary speech and social scientific discourse to keep pace with the reality that needs to be discussed. "Technology", therefore, is applied haphazardly to a staggering collection of phenomena, many of which are recent additions to our world. One feels that there must be a better way of expressing oneself about these developments, but at present our concepts fail us.

One consequence of this state of affairs is that discussions of the political implications of advanced technology have a tendency to slide into a polarity of good versus evil. Because there is no middle ground for talking about such things, statements often end up being expressions of total affirmation or total denial. One either hates technology or loves it. (Winner, 1977, p.10)

Within the confines of this section of the article I choose not to provide a mass of evidence of the existence of these two orientations towards technology and perhaps this will prove to be no bad thing, for each of us in our own institutions is doubtless surrounded by colleagues who could be collected within one or the other camp. The lecturer who continues to avoid using even such items as overhead projectors on the one side and on the other the educational technologist who carries and uses any new device that appears, rather as a teenager might show off her new boyfriend. The computer programmers who become:

... so involved with computers that they become an end in themselves. They forgot the purpose of the computer is to do something and become much more interested in maintaining system for its own sake ... they get so wrapped up in it they have no life outside the computer. (Wrege, 1983, p.96)

Weizenbaum when speaking of the hacker points out that: 
The hacker seeks the same type of control that cyberphobes shy away from, playing a role as "the creator of universes for which he alone is the lawgiver ... programmed scripts compliantly obey their laws and vividly exhibit their obedient behaviour. No playwright, no stage director, no emperor, however powerful, has ever experienced such absolute authority to arrange a stage or a field of battle and to command such unswerving dutiful actors or troops. (Wrege, 1983, p.96)

One grasps for that from which the other shys away. Here we get a feeling for what Shepard (in Mathews, 1980) refers to as the "janus-faced" image of technology.

Zuboff, speaking of the introduction of computers to the work place, argues that:

Hostility is generated when workers feel they've lost control over job conditions and environments and it usually surfaces soon after computerization is implemented. People feel undermined when they realize valued skills and talents can be taken over by computers. This situation exacerbates the issues of power and powerlessness found in all levels of organizational life. (Wrege, 1983, p.95)

As yet it would appear that technophilia and technophobia are generalized expressions of purely personal orientations towards technology but what if we were to discover that this was not the case and that these opposed perspectives were simply one more instance of the articulation of an awareness that differentiation between the haves and have-nots is on the increase rather than the decline.

\section{Consider the following general statement from Eric Entemann et al.:}

Those who have an interest in controlling workers in order to increase efficiency would have us believe that the technology of production lines, secretarial pools, pollution, hierarchical control is good, that it is necessary, and that it is inevitable. While 'progress' is sold to us as improving the quality of life in the form of products that relieve us from monotonous labour, move us faster through the air, cook our food in seconds - it has, in fact, alienated us and degraded our lives. Technology for most of us is mysterious and awe-inspiring. Taught to believe in and trust a small group of specialists who supposedly hold the golden key of knowledge, we increasingly relinquish control over our own lives, and are left atomized, frustrated, suffering a vague sense of loss and resentment. (1977, p.319)

Perhaps a specific example of the introduction of a new technology is relevant here. Whilst the example isn't drawn from the distance education area I shall, for reasons which will become clear, return to it again later in this article. The example is that of the introduction of snowmobiles in Lappland and Alaska. In their careful analysis of this process Pelto and Muller-Wille (1972) conclude that in certain areas those people who cannot 
buy snowmobiles appear to be at a serious disadvantage. They argue that the introduction of these machines to those areas is likely to increase the differentiation between the haves and the have-nots. But more of snowmobiles later. At this point I would like to turn to the more analytic section of this article.

2. In this section I intend to present certain rudimentary ideas concerning theories of social class. They will be sufficient, however, to present us with a firmer grounding for our comprehension of the technophilic and technophobic perspectives and also they will provide us with some systematic alternative frames through which we can later focus upon the notion of a 'technological society'.

Consider the diagrammatic representation of interpretations of class structure presented in Ossowski's work (1961, p.152):

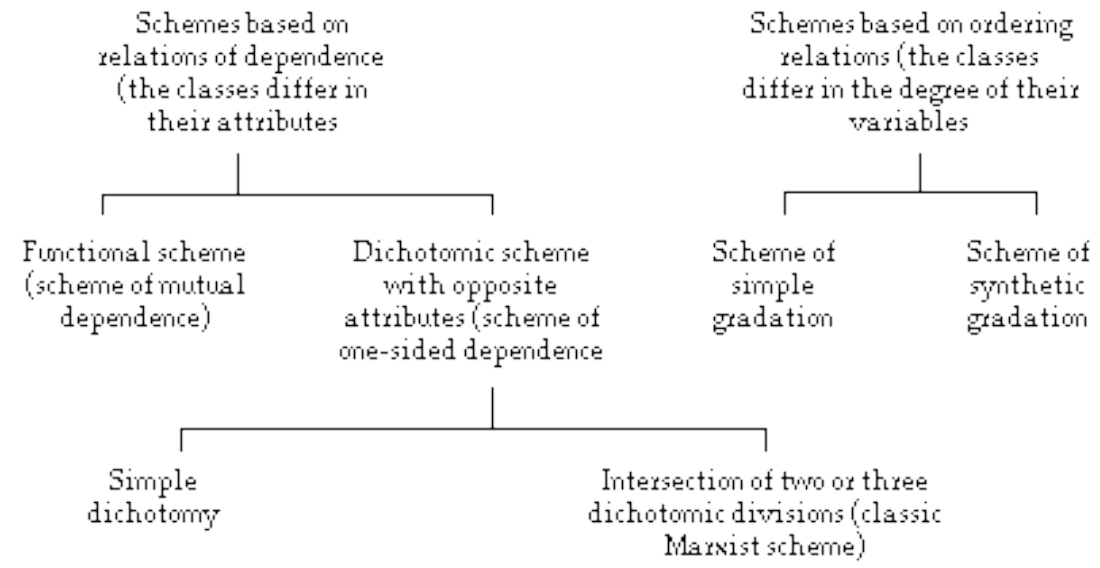

Figure 1: Types of interpretation of class structure

My contention is that the opposed responses to technology can be located within this framework as interpretations of the type that indicate relations of dependence of the dichotomous kind which could be viewed either as a simple dichotomy in its own right, or as one additional dichotomous division which intersects with others.

The following series of brief quotations may help to persuade those, if any, who would reject this view to give it further thought.

Hallblade and Mathews for example, remind us that:

Information is power, and computers mean information. The centralized accumulation of data permits the concentration of enormous power in the 
hands of those with access to the computer. The very existence of sophisticated computers leads to a power gap between those trained to use and understand them and those who are not. (1980, p33)

Dickson refers us to the fact that:

The British Society for Social Responsibility in Science points out in its policy statement that 'Scientific and technical knowledge is an important source of power, but only large institutions have the resources needed to exploit it ... thus science is used directly to increase the power of the already powerful and to frustrate the expectations of the powerless. (1974, p.30)

\section{Martin and Norman indicate that:}

The gifted will have immensely powerful facilities available to them in the society we visualize, while those who either do not like or do not understand the machines may become increasingly bewildered and hostile. (1973, p.423)

Hill reminds us of the managerial implications when he states that:

It has now become clear that technology is one of the means by which managers control the activities that occur within their firms, which, by implication, suggests that when managers choose a particular technology they also choose how their firms are to be controlled. (1981, p.105)

An increasing awareness of this shift of control is indicated by Macpherson when he says that:

There is a growing disbelief in technology as the cure-all, in view of the damaging uses to which managed capitalism puts it (pollution and ecological destruction). There is a growing restiveness within the labour force over its subordination to organization and technology (wildcat strikes and shop-steward militancy). And as the state runs into deepening fiscal difficulties, there is likely to be increasing restiveness among some of those sections of the public who were said ... to be fairly easily persuaded of the legitimacy of the state as long as the money held out, i.e. workers in the public sector, as expenditures on hospitals, schools, etc., are cut back, so reducing or cancelling their relative job security. (1981, p.73)

Clearly contemporary policies in Higher Education, and responses to these policies, can be examined in these terms. But the very function of education has also been defined by some in relation to this dichotomy. Consider the following proposal:

The accelerating industrialization of society not only creates directly technical and scientific occupations in ever greater numbers, importance 
and variety, but also causes traditional activities of all kinds to become permeated with science and technology.... Thus education is increasingly called upon to produce not only technicians but a population sympathetic to technological advance. (Reeder, 1981, p.191)

The education sector may be called upon in this way precisely because of the threats to political stability as outlined by Williams:

The political stability of technological societies may be threatened from many directions. First, by the hopelessness and alienation of the technologically excluded sub-poor. Second, by the intellectuals who reject the 'smothering compulsion' of technological society. Third, by the chaos of competitive and incessant economic group demands. Fourth, by failure, for whatever reason, to maintain the option of economic growth. Fifth, by inability to ensure that the myth of purposefulness is reborn in every generation, or replaced by an acceptable alternative. (1971, p.60)

By grounding the notions of technophilia and technophobia within this broader debate we can better understand how large a hurdle exists before a worthy recommendation such as that which follows from Stephen Hill might be implemented:

In an economic system based on co-operation and trust rather than hostility, technological progress could have a liberating rather than a degrading effect. (Hill, 1981, p.30)

As Kuttner points out in a succinct and practical fashion:

How much less ambiguous a blessing technology would be against a background of full employment. (1984, p.34)

Given current levels of unemployment (especially when standard statistics are supplemented with estimates for hidden unemployment and underemployment) we can perhaps better understand how technology as a blessing is transformed into a blight and how the technophiliac is somewhat less than welcomed by the majority. This may go some way to account for the comparative lack of technological change in the sphere of education.

I hope by now to have provided sufficient argument and evidence to support my contention that the notions of technophilia and technophobia can assist us in our understanding of the context within which educational technologists work. It would appear that certain combinations of versions of self interest and of the effects of technological change make either perspective seem quite reasonable/rational. For example the technophile would probably Willingly assent to the viewpoint expressed by Kasper in Australia at the Crossroads: Our Choices to the Year 2000 when he states that: 
Technological change admittedly creates frictions and adjustment burdens, but those countries that adapt most quickly will also be those that will reap the benefits that always reward pioneers. (1980, p.169)

Whereas the technophobe would very likely agree with the sentiments expressed by Roberts:

Critics of modern technology broadly agree in levelling three general charges: it is too big, too centralized and too complex. It is not hard to expose the social evils to which these features lead. The workers expend their energies on fragmented tasks which have no meaning for them, in a production process generally so large-scale and intricate that it escapes the comprehension of all save a privileged few. The consumers are "persuaded" and programmed to serve the ends of that productive machinery, whose enormous capital requirements make it unthinkable that the disposal of the product be left to the whims of a free, unmanipulated market. Increasingly the citizens lose any degree of autonomy, and become helplessly dependent on the centralized institutions called for by that centralized, gigantic economic machine. (1979, p.79)

3. In this, the third section of the paper, I want to, even if only briefly, propose that the two commonly held, influential, and seemingly reasonable perspectives outlined previously are far from reasonable for each relies upon untenable assumptions. Each relies upon a form of technological determinism;

the technophile commending the process and the outcome whilst the technophobe criticizes both process and outcome. An optimistic and a pessimistic orientation. However, as I have argued elsewhere (Campion, 1986, p.103) neither optimism nor pessimism is an adequate response for both claim to know too much about (a) what will happen and (b) what is good or bad. Both perspectives can generate an unduly passive orientation towards the future. By treating technology as an independent variable we effectively remove it from our control and by doing so allow it to be perceived as either a monster or a miracle.

Furthermore this specific form of determinism which treats technological change as an independent variable effectively ignores the links between technological innovations and the socio/economic/political context in which they were generated.

Dickson argues that specific technologies are far from politically neutral when he states that:

The institutionalization of technology has meant that the choice of particular machines, or at least the control over this choice, remains in the hands of a dominant social class. And since technological innovation, as has 
already been suggested, is only carried out to the extent that it coincides with and maintains the interests of this class, new machines will only be introduced within the constraints that are imposed on the activities of the individual members of society. (Dickson, 1974, p.177)

Barry Jones, at one time, Australian Minister for Science and Technology, argues against the deterministic position in the following fashion:

The false premise on which technological determinism is based asserts that technology is a single entity, monolithic and incapable of being differentiated. There is no suggestion that there are varieties of technologies, or that it is possible for nations to choose between them. This is the 'cargo cult' view of technology; we wake up one morning to find a computer in the garden, it has arrived impersonally and we must take it or leave it as we find it. Technological determinists argue that if we reject high technology we will be punished; if we accept it, the pre-recorded birds will sing all day, and artificial lighting will abolish night. (1983, p.216)

Elsewhere Jones states that:

A false dichotomy is forced on us which says that technology equals rationality and, therefore, opposition to (or proposals to modify) technology equals irrationality. (1983, pp.210-211)

This dichotomy leads some to adopt the technophobic response illustrated by Dickson:

There is also the contemporary myth that our social problems are in many ways caused by advanced technology, in other words, that advanced technology has become intrinsically antihuman; although this myth ignores the political factors behind the oppressive nature of technology in advanced capitalist societies, it nevertheless comes close in a number of respects to the interpretation ... Dickson proposed ... by refusing to separate the nature of technology from the uses to which it is put. (1974, p.184)

Prejudice can also lead to the superficial and potentially hypocritical antitechnological perspectives of those who forget that as Dickson points out:

Virtually our whole daily routine is achieved through machines. Shaving, making coffee, frying an egg, catching a bus, or a train to work, speaking on a telephone, watching television, each of these actions are achieved through the use of an element of technology. (1974, p.176)

Conversely however, by remembering the degree to which our environments incorporate a reliance upon items made by humans we can grasp more clearly why the debate about technology is crucial to our futures. As Dickson says: 
Technology does not just provide, in its individual machines, the physical means by which a society supports and promotes its power structure; it also reflects, as a social institution, this social structure in its design. A society's technology can never be isolated from its power structure, and technology can thus never be considered politically neutral. (1974, p.180)

The snowmobile example can also help us to realize that the ecological features of the situation into which a change is introduced also need to be taken into account. So for example in the areas of Lappland where skidoos (snowmobiles) came to be used for reindeer herding the degree of forestation was a significant variable in their application and in Alaska where reindeer herding wasn't their users role a different set of ecological factors came into play. For example a ski-doo, unlike dogs, will not stop at the edge of a crevasse (Russell \& Pelto, 1972). Clearly we need to understand the particular context in which an educational institution is situated if we are to understand how a technological change will affect it.

In this section I have intended to undermine both the technophilic and the technophobic perspectives by questioning an assumption which is common to both. However, before turning my attention to versions of the 'technological society' it is pertinent to mention the distinction used by Mandel between partial rationality and overall irrationality for this may also remind us to pay heed to the broader issues.

Mandel states that:

\begin{abstract}
If economic rationality is ultimately regarded as economy of labour-time-as saving of human labour-then the inherent contradiction in capitalism between partial rationality and overall irrationality re-emerges in the paradox that the compulsion to save the maximum amount of human labour in the factory or the company leads to increasing waste of human labour in the society as a whole. The real idol of late capitalism is therefore the 'specialist' who is blind to any overall context. (1972, p.509)
\end{abstract}

4. By now the existence of any consensus regarding the meaning of the term 'technological society' must clearly be in question.

We have not only become aware of polarized responses to technology which themselves generate and rely upon utopian and dystopian versions of the future, but we have also been reminded of the irrationality of treating technology as an undifferentiated whole.

Perhaps we can best understand the sub-theme of the conference referred to at the beginning of this paper as requesting us to consider alternative futures and their implications for education. If we need reminding of the importance of this activity the following quotation from Hummel may assist: 
By their very nature, every educational project and every measure taken in this field looks to the future.... Any planning of education presupposes the existence of a political intention, for it is aimed at implementing a project of society. (1977, p.181)

Hummel goes on to argue that:

The future of education depends more on external factors than on endogenous elements in education systems. The political, economic, social and cultural contexts will determine the education of tomorrow, as they do today. (1977, p.182)

What can we say about the contexts within which the education of tomorrow will be situated? If we refer briefly once again to Richard Badham's (1984) work The Sociology of Industrial and Post-Industrial Societies we find reference to Post-Capitalist theories, theories of Post-Classical Capitalism, theories of Post-Industrialism, theories of HyperIndustrialization and theories of De-Industrialization all with their advocate and adversaries and with further detailed subdivisions. So for example the notion of Industrial Society is said to encompass the notions of affluent society, manufacturing society and complex society.

Educational technologists who choose to ignore debates of this kind can hardly be well placed to deal with the fears of the technophobes if those fears are grounded in specific versions of the societal outcomes of technological change, however vague, ill-informed or ill-articulated those assumptions might be.

At this stage I would simply suggest that the proposals of education technologists are likely to be contingent upon the tasks attributed to the education system. Whether, for example, "Education [is perceived] as a discrete experience within and end-on to schooling" or "...as a continuous life long process of learning" (Watts, 1983, p.185). Either of these two policies could be well served by educational technologists but technology generated and organized in the service of the former list might hinder the latter, and vice-versa. As Winner points out "Different ideas of social and political life entail different technologies for their realization" (1977, p.325)

One of the consequences of the processes associated with the specific form of technological change which has been occurring in the West has been a restructuring of the work force. More precisely this process involves changes in the type of work performed, changes in the relations between occupations and changes in the proportions of the population involved in paid employment and of those not involved, together with differing demographic profiles for each of these sectors. So, for example, certain crafts which involve a multitude of skills have been replaced by more narrowly specialized occupations which involved a more limited range of 
activity. The blacksmith for example is replaced by the process worker on a production line.

Now clearly this process will have and has had effects upon the purposes of the formal education sector, but we need also to notice that each of the types of changes just referred to at the general societal level is also likely to have implications within the education sector. In essence what I am saying is that just as we now need to go to Pioneer World or a museum to see a blacksmith, so also in the not too distant future we might need to refer to an historical videodisc to see an academic as contemporarily understood. The shift from a discipline-based to a process-based division of labour currently occurring within areas such as distance education is likely to be of far more general application.

So on an intra-institutional level, the separation of course preparation from course administration and of both from tutoring and assessing, can lead to a division of labour which in Durkheimian terms produces a requirement for organic rather than mechanical solidarity. Furthermore, on an interinstitutional level, the increasing division between research, teaching and administrative functions which is exemplified in the shift towards centres of excellence in research being created in institutions A and B whilst institutions $\mathrm{C}$ and $\mathrm{D}$ are recognized as, for example, general providers of distance education, and whilst new national committees are set up to co-ordinate and administer these more complex divisions of institutional roles, are all indicative of structural changes which are contingent to a large degree upon developments in educational technology. I should perhaps point out that I am not by any means necessarily commending this direction of development, rather I am trying to illustrate that the work of educational technologists is not only another example of this more specialized division of labour but also that it has a crucial role in limiting or expanding the availability of choice in relation to the type of division of labour that will be available in the education sector in the future. Now clearly I am not saying that educational technologists have overall responsibility for this process or that they can act in an autonomous fashion. However if each of us denies any responsibility for the whole then we should hardly be surprised if it appears that technology, rather than humans, determine what will happen.

The following comments of Robert Boguslaw quoted in Shepard's article may help us to reorient our agenda:

(1) Our first concern should be about the impact of the social order on technology rather than the reverse. (2) Human beings are in control of their future. We should be asking which people and what set of values will control our destiny. (3) Should people be enslaved or destroyed, it will be by other people. There are no inanimate villains. (4) Technology is never neutral. It embodies a set of human values often latent, obscure, or 
deliberately disguised. "One of the tasks of well motivated individuals is to expose the precise nature of value choices embodied in various forms of technology". (5) Technology cannot bring obsolescence to human values. "Humanistic values can be made obsolete only by antihumanistic or nonhumanistic values". (6) Technology creates no new values. Old values may be strengthened or distorted. (7) Serious students of technological change must participate in value decisions. (Shepard in Mathews 1980, p.153)

Given the current trend towards an increasing separation of research from teaching, and the increasing specialization of labour mentioned in relation to teaching, it seems to me likely that today's Universities may well be remembered in the not too distant future much as the village common is today - and that this will be a consequence of academia failing to generate any effective alternative view, to paraphrase Jones. (1983, p.210)

Perhaps to draw the paper to a close I should refer once again to the introduction of snowmobiles into the reindeer herding process in Lappland. Winner, drawing upon Pelto's work, states that:

Possibly as a result of the physiological strain placed on pregnant female reindeer by the stampede running of mechanized roundups, the fertility and population of the herds fell off sharply. (Winner, 1977, p.87)

I wonder whether innovative thinkers could be treated as analogous to pregnant reindeer? If so we need to ensure that our seemingly more efficient and effective educational processes do not have a similar result.

\section{References}

Badham, R. (1984). The Sociology of Industrial and Post-Industrial Societies. Current Sociology, 32(1), 62.

Campion, M. (1986). Worry: A Maieutic Analysis. In the Avebury Series in Philosophy. Aldershot: Gower Publishing Co.

Cooley, M. (1980). Architect or Bee. Langley Technical Services.

Dickson, D. (1974). Alternative Technology and the Politics of Technical Change. Glasgow: Fontana.

Entemann, E. et al. (1977). Alternative Technology: Possibilities and Limitations. In G. Boyle, D. Elliott, \& R. Roy, The Politics of Technology. London: Longman in association with The Open University Press.

Hallblade, S. \& Mathews, W.M. (1980). The Computer and Society. In W.M. Mathews, Monster or Messiah, University of Mississippi, p.33.

Hill, S. (1981). Competition and Control at Work. London: Heinemann Educational Books.

Hummel, C. (1977). Education Today for the World Tomorrow. Switzerland: UNESCO.

Jones, B. (1983). Sleepers, Wake! Technology and the Future of Work. Oxford University Press. 
Lowi, T. J. (1982). The Political Impact of Information Technology. In T. Forester, The Microelectronics Revolution, Oxford: Basil Blackwell.

Kasper, W. et al. (1980). Australia at the Crossroads: Our Choices to the year 2000. Harcourt Brace Jovanovich.

Kuttner, R. (1984). The Economic Illusion: False Choices between Prosperity and Social Justice. Massachusetts: Houghton Mifflin Company.

Mandel, E. (1972). Late Capitalism. London: NLB.

Macpherson, C.B. (1981). Do we need a theory of the state? In Dale, R., Esland, G., Ferguson, R. and M. MacDonald, Education and the State. Volume 1: Schooling and the National Interest. Basingstoke: The Falmer Press in association with The Open University Press, p.73.

Martin, J. \& Norman, A.R.D. (1973). The Computerized Society, Harmondsworth: Penguin Books Ltd.

Mathews, W.M. (1980). Monster or Messiah, University of Mississippi.

Ossowski, S. (1961). Class Structure in the Social Consciousness. London: Routledge and Kegan Paul.

Pelto, P.J. \& Muller-Wille, L. (1972). Snowmobiles: Technological Revolution in the Arctic. In B.H. Russell, \& P.J. Pelto, Technology and Social Change, New York: Macmillan.

Reeder, D. (1981). A Recurring Debate: Education and Industry. In Dale, R., Esland, G., Ferguson, R. and M. MacDonald, Education and the State. Volume 1: Schooling and the National Interest, Basingstoke: The Falmer Press in association with The Open University Press, p.191.

Roberts, A. (1979). Technology as Hope and Threat, Arena, No.53.

Watts, A.G. (1983). Education, Unemployment and the Future of Work. Milton Keynes: Open University Press, p.185. Williams, R., (1971). Politics and Technology. London: Macmillan.

Winner, L.,(1977). Autonomous Technology: Technics-out-of-control as a theme in political thought. Cambridge: Massachusetts Institute of Technology.

Wrege, R. (1983). In D.L. Van Tassell, and C.L. Van Tassell, The Compleat Computer. Science Research Associates, Inc.

Author: Dr Michael Campion is a Senior Education Officer in the External Studies Unit at Murdoch University at Murdoch in Western Australia.

Please cite as: Campion, M. G. (1989). Technophilia and technophobia. Australian Journal of Educational Technology, 5(1), 23-36. http:/ / www.ascilite.org.au/ajet/ajet5/campion.html 